\title{
Compressive Behavior of Frame-Stiffened Composite Panels
}

\author{
Nicolette P. Yovanof \\ The Boeing Company, Seal Beach, CA, 90740 \\ and \\ Dawn C. Jegley ${ }^{\dagger}$ \\ NASA Langley Research Center, Hampton, VA, 23681
}

\begin{abstract}
New technologies are being developed under NASA's Environmentally Responsible Aviation (ERA) Program aimed at reducing fuel burn and emissions in large commercial aircraft. A Pultruded Rod Stitched Efficient Unitized Structure (PRSEUS) concept is being developed which offers advantages over traditional metallic structure. In this concept a stitched carbon-epoxy material system is employed with the potential for reducing the weight and cost of transport aircraft structure by eliminating fasteners and producing a more damage tolerant design. In addition, by adding unidirectional carbon rods to the top of stiffeners and minimizing the interference between the sandwich frames and the rodstiffened stringers, the panel becomes more structurally efficient. This document describes the results of experimentation on a PRSEUS panel in which the frames are loaded in unidirectional compression beyond the local buckling of the skin of a Hybrid Wing Body (HWB) aircraft. A comparison with analytical predictions and the relationship between these test results and the global aircraft design is presented.
\end{abstract}

\section{Introduction}

$\mathrm{T}$ he current focus of the NASA Environmentally Responsible Aviation Program (ERA) is the Hybrid or Blended Wing Body (HWB/BWB) vehicle. A hybrid wing body aircraft employs advanced technologies to achieve a highly integrated airframe that is capable of substantial aerodynamic performance improvements resulting in reduced fuel burn and pollutants compared to today's aircraft. ${ }^{1}$ The key structural challenge of a HWB aircraft is the ability to create a cost and weight efficient, non-circular, pressurized shell. Airframe weights are kept low through the extensive use of advanced composite materials resulting in architectures that are appreciably lighter than comparable aluminum designs.

A global analysis of a HWB vehicle reveals that it has high loading in the span-wise direction in addition to the internal pressure loading while the chord-wise direction loading is low. The span-wise loading, which differs from loading seen in a traditional cylindrical fuselage, is primarily due to the bending moment induced by flexure of the wings during maneuvers which are unique to a hybrid wing body, flat panel configuration. This loading is described in Fig. 1. To support the biaxial loading condition, integral stiffeners in both the span- and chord-wise directions are required.

The HWB structural development program uses a building block approach to design, analyze, build, and test components as shown in Fig. 2. One area of interest in particular is the behavior of span-wise specimens loaded in compression. Compression-loaded frame specimens are circled in Fig. 2. Evaluation of the frame components began with analysis and testing of a series of small scale coupons to demonstrate stability under axial compression loads and is now focused on a two-frame, realistic-length compression specimen. This paper focuses on the two-frame span-wise, compression specimen test and analyses efforts conducted by Boeing and NASA.

The objective of the compression test was to confirm the advantages of the integral frame design approach to carry HWB span-wise loads. The purpose of this test was to validate the compressive load-carrying capability of a crown panel loaded in the span-wise direction by simulating panel conditions encountered during the 2.5-g pull-up airplane maneuver. This paper considers the unique, high compressive axial loads of the near-flat panel design on a

\footnotetext{
${ }^{*}$ Aerospace Engineer, Member, AIAA, Boeing Research and Technology, 2600 Westminister Ave, M $\backslash \mathrm{S}$ 110-SK56.

${ }^{\dagger}$ Senior Aerospace Engineer, Associate Fellow, AIAA, Structural Mechanics and Concepts Branch, Mail Stop 190.

1

American Institute of Aeronautics and Astronautics
} 
HWB aircraft and the column stability advantages of the integrated design approach through analysis and testing of a 92-inch long 30-inch wide, 2-frame span-wise compression panel. The primary purpose of this subcomponent test was to assess the buckling stability of the integral frame feature.

\section{Structural Concept}

In order to close the design on the HWB with a light-weight, cost-effective, manufacturable concept, a PRSEUS configuration, shown in Fig. 3, was selected. Trade studies indicate that significant weight savings can be achieved through the use of PRSEUS technology. ${ }^{2}$ PRSEUS is an integral panel assembly produced outside of an autoclave. PRSEUS uses dry warp-knit fabric materials stitched together to create a preform of the full structural panel such that all materials can be co-cured without the use of Inner Mold Line (IML) tooling. Skins, flanges, and webs are composed of layers of graphite material forms that are prekitted in multi-ply stacks using Hercules, Inc. AS4 fibers. Several stacks of the prekitted material are used to build up the desired thickness and configuration. Specimens are stitched together using Vectran fibers. Stiffener flanges are stitched to the skin and no mechanical fasteners are used for joining. To maintain the panel geometry during fabrication, first stiffeners and then the skin are placed in a stitching tool for assembly prior to moving to a curing tool for consolidation in the oven. The rod-stiffeners running in the axial direction consist of webs with a bulb of unidirectional carbon fiber rods at the top of the web. AS4 carbon fiber overwraps surround the bulb. The frames in the lateral direction are foam filled.

The prekitted stacks used in the PRSEUS skin and stiffeners have approximately $44 \% 0$-degree, $44 \% \pm 45$ degree, and $12 \%$ 90-degree plies. The thickness of each stack of material is approximately 0.052 inches. PRSEUS panel are currently made from AS4 fibers and HexFlow VRM 34 resin. $^{2}$ The pultruded rods are Toray unidirectional T800 fiber with a 3900-2B resin and the frame stiffeners are filled with Rohacell foam. In the current design, the $44 \%$ 0-degree orientation of the skin is parallel to the frames in the span-wise direction for the HWB in order to make the most effective use of the integral panel configuration. Sketches of the cross section of a rod-stiffened stringer and a frame are shown in Figs. 4 and 5, respectively. Rod-stiffened stringers have a 3.4-inch wide flange, a 0.104 -inch thick stiffener web and a 1.5 -inch tall stiffener. The nominal diameter of the pultruded rod is 0.375 inches and the nominal thickness of the overwrap is 0.052 inches. Flange thickness is half the web thickness. Frames have a 3.9-inch wide flange, a 0.5 -inch foam core and a 0.104 inch thick web on each side of the foam. Frames are 6 inches tall. For both the rod-stiffened stringers and the frames, one stack of additional material is added under each flange and labeled as a tear strap in the figures. This reinforcing stack covers the same area of skin as the stiffener flange for both types of stiffeners. Since PRSEUS panels are fabricated in an oven rather than in an autoclave the size of a single unitized part is not limited to the size of an autoclave. In addition, while the Outer Mold Line (OML) is a precisely machined metal tool, the IML is formed by the use of vacuum bags which are cut and positioned to hold the stiffeners in place during the curing process. These curing features allow for reduced cost of fabricating large components with few structural joints required in the final assembly. This manufacturing approach is described in more detail in Ref. 2.

An additional benefit of this concept is the damage arrestment capability of the stitching which increases the load carrying capability and allows for the use of a post-buckled skin. ${ }^{3}$ In addition to the strength benefits of a unitized panel, the PRSEUS stringer is optimized for fuselage loading with the continuous 0-degree fiber pultruded rod in the cap and the frame has deep sections raising the panel's neutral axis for bending capability and providing an uninterrupted load path. The continuous rod passes through a slit or keyhole in the frame to minimize loss of stability and optimize load transfer, as shown in Fig. 3. The PRSEUS configuration is the critical technology needed to close the HWB design due to the confluence of light weight composites, damage arresting capabilities, and costeffective manufacturing techniques inherent in the concept. Because the frame and skin stacks are infused as a singular element, without shear clips or fasteners, the ensuing panel geometry is a highly effective component under compressive loading. The PRSEUS frame design is effective in stability because it is closed-cell, without a shear clip or fasteners, and able to utilize a portion of the effective skin. Earlier studies involving stitched technology are presented in Ref. 3-12.

The analysis results were used to assess the buckling stability of the PRSEUS frame by simulating the span-wise compression loads caused by the pull-up wing-bending maneuver $(2.5-\mathrm{g})$. For the ultimate load case, the expected running load under compression would be 5,000-lbs/in. With the baseline PRSEUS frame spacing of 16 inches in the aft region where the span-wise loads are the highest, this comes out to approximately 80,000-lbs per frame, or about 160,000-lbs for the 2-frame geometry used in the specimen design. 


\section{Element Level Testing}

Preliminary evaluations of the frame configuration were conducted on four, single-frame compression specimens where the frame spans three stringer bays as described in Ref. 2. Single-frame specimens indicated in Fig. 2 by the two smaller red circles. The main purpose of these single-frame compression tests was to find the failure load of the specimen and correlate initial analysis predictions with the empirical results. Two specimens were tested statically and two were fatigued before final static testing. Testing of all four of the specimens showed that the frame can meet the loading requirements as dictated by the global analysis, regardless of cycling. Typical load-strain relationships are shown in Fig. 6 for two single-frame specimens, each shown as a dashed line (the dashes are coincident for load less then 55 kips so the line appears solid). The filled circles represent specimen failure. Each specimen failed across the frame web initiating at the keyhole above the stringer, as shown in Fig. 7, at a strain value of around 0.0067 in/in. These results also provided insight into the failure mode of the frame under compression. After obtaining results from the single-frame specimens demonstrating they can withstand the required loads, the next step was to evaluate larger, more realistic specimens.

\section{Subcomponent Panel Description}

The subcomponent panel is a 2-frame, 15-stringer, 30-inch by 92-inch PRSEUS panel with a one-stack skin where the 0-degree orientation aligned with the frames. Stiffener cross sections are shown in Figs. 4 and 5. The specimen geometry and photos of the IML of the panel and an end view of the cross section are shown in Fig. 8. The frames are spaced 20 inches apart and the stringers are spaced six inches apart. The frame spacing of the specimen was 20 inches as opposed to 16 inches in the vehicle model to leverage existing tooling. Extra features were added to the basic panel described above to smoothly transition the applied end loads into the nominal test section of the panel. Additional skin stacks and stitches are added at the ends to compensate for local stress concentrations due to load introduction effects. Extra doubler stacks were added to the end of the stringer bays and around the frame caps extending all the way down to the third stringer. An external OML stack was also added extending down to the first end stringer. The added stack material at the ends is shown in Fig. 8. The fabrication of this panel is described in Ref. 13. Prior to testing, each end of the specimen was potted in 1.0-inch-deep epoxy compound and the ends were ground flat and parallel to each other to ensure uniform load introduction.

The initial shape of the center region of the panel was determined prior to testing to identify initial conditions and out-of-plane imperfections in the panel. The initial geometry of the OML surface was recorded while the panel was standing in the test machine and is shown in Fig. 9. The red lines in the figure indicate strain gage wires and not the panel surface. This data shows that the variation from a flat surface consisted of approximately \pm 0.02 inches in the skin bays between stiffeners.

\section{Test Procedure and Instrumentation}

The specimen was tested at room-temperature in a dry condition under compressive axial loads at NASA Langley Research Center in a 1-million-lb capacity test machine. The pristine panel was subjected to a single test to failure using a load rate of $15,000 \mathrm{lb} / \mathrm{min}$ to simulate static loading.

Side edge restraints were used to stabilize the free edges of the panel by using a smooth surface along the OML approximately 0.5 inches from the edge of the panel and cap screws prevented the thin gauge skins along the IML edge from buckling as the panel specimen was loaded. Since the cap screws did not penetrate the panel, but just touched the skin on the IML side of the specimen, load is not transferred into restraint members. A small gap between the potting at the top of the panel and the restraint prevented the edge restraints from picking up any applied load. Teflon tape was applied between the restraints and the panel to allow the panel to slide as it shortened during loading. These edge restraints are shown in Fig. 10.

In preparation for the test, the specimen IML surface was painted flat white, including skin, frame webs, stringer webs, and all flanges. The paint on the IML surface was used to aid in the crack propagation detection during the test. In addition, a black and white speckle pattern was applied to the OML so that a vision image correlation system could be used to track full-field displacements and calculate full-field strains on the OML surface. The Video Image Correlation in 3 Dimensions (VIC-3D) system viewing area was the entire region painted with the speckle pattern of approximately 40 inches in the axial center of the panel and the full width between the edge restraints. Pre- and posttest photos of the specimen and set-up were taken and a standard speed digital video with sound was taken of the OML side during loading. 
Electronic displacement indicators were used to monitor panel deflection during the test. Nine linearly variable displacement transducers (LVDTs) measured displacement when the specimen was under load. Three LVDTs were placed on the platen to measure panel shortening, four monitored the frame for in-plane displacement, and two measured out-of-plane displacement of the skin. These measurement locations are shown in Fig. 11a. Eighty strain gages were attached to the OML, IML skin and frames. Representative strain gage locations are shown in Fig. 11b.

The panel was loaded statically to failure with loading held at limit load for 3 seconds. The panel is shown in the test fixture prior to the test in Fig. 12. Data for the strain gages, and displacement measurement devices were recorded at $5 \mathrm{~Hz}$ and VIC results were recorded at a rate of $1 \mathrm{~Hz}$.

\section{Subcomponent Panel Analysis}

A finite element analysis was performed using the computer code MSC.NASTRAN ${ }^{14}$ to predict buckling and failure loads, mode-shapes, and to determine the optimum strain gage placement for testing. A linear approach was used to check the onset of skin buckling and to assess initial strength margins. Nonlinear analysis was then used to determine overall panel buckling modes and to assess local strength failures in critical regions. The resulting failure loads were compared to one another to determine whether the panel was strength or stability critical. The Finite Element Model (FEM) contained 39,096 shell elements to represent the skin, webs and flanges, 1,128 rod elements to represent the pultruded rods, and 36,632 solid elements for the foam core and is shown in Fig 13. The model includes the 30-inch wide and the 90-inch long test-section. In this model, the center 19-inches of the specimen has a finer mesh to obtain more precise results in the test region of the panel. This finer mesh allows more accurate results in areas where stress concentrations are anticipated. The panel has one short edge fixed and a compressive load applied to the other end through an enforced displacement using RBE2 elements. The restraints on the unloaded edges were modeled as using beam elements attached to locations one inch from the edge of the panel to correspond to the location of the cap screws in the restraint fixture. These elements only restricted the out-of-plane motion of the panel.

\section{Results and Discussion}

Displacements, strains, buckling behavior and failure modes are presented herein. Full field experimental results and analytical fringe results are shown to evaluate displacement and strain distributions for post-buckling behavior and immediately prior to failure. In addition, a comparison between locations of peak strains and photographs of the failure are shown.

\section{A. Displacements and Buckling}

Initial results from the nonlinear analysis show that local buckling of the skin occurs at 59,000 lbs, which is approximately $30 \%$ of ultimate load as required by the HWB design requirements. Global buckling occurs at approximately 207,000 lb. Local and global mode shapes are shown in Fig. 14.

Predicted displacements at selected location on the skin and the frames as a function of the compression load are shown in Fig. 15. The dramatic changes in deformation patterns are seen in the skin gage results at a load of approximately 59,000 and in the frames at $207,000 \mathrm{lb}$, corresponding to the predicted buckling loads. Since no global buckling occurs prior to the required load of $200,000 \mathrm{lb}$, this panel was expected to support the required $80,000 \mathrm{lb} /$ frame requirement for the HWB structure.

The measured full-field out-of-plane deformations of the OML for load levels 18,000, 25,100, 88,000, 130,000 and 147,000 lb are shown in Fig. 16. These results indicate that out-of-plane deformations occurred in the skin at load less than $18,000 \mathrm{lb}$ and the out-of-plane deformations grew as the loading increased. Maximum out-of-plane deformations occurred at the midbay of the skin with a magnitude of approximately 0.25 inches prior to failure at approximately $147,000 \mathrm{lb}$. The midbay LVDTs recorded an out-of-plane displacement which indicates buckling of the skin at a load of approximately 23,000 lbs, shown in Fig. 16. This load is significantly less than the predicted local buckling load. One explanation for the low buckling load is that the analysis did not consider the initial imperfect shape of the panel. Even though the initial deformation was only 0.02 inches, that value is approximately $40 \%$ of the skin thickness, so it is not surprising that local buckling between the stiffeners occurred at a lower load than predicted. However, one point of the test was to demonstrate that the panel could support load into the post buckling range so despite the early buckling, the panel demonstrated its ability to support load in the post-buckling condition. LVDT's on the frames recorded little deformation for load less than 120,000 lb with no indication of failure until the global failure of $147,000 \mathrm{lb}$. This result indicates that the panel withstood approximately six times 
the local buckling load prior to failure, or approximately $73,000 \mathrm{lb} /$ frame. This load is approximately 10 percent less than the goal of $80,000 \mathrm{lb} /$ frame.

\section{B. Strains}

Since audible indications of possible failures occurred at 90,000 lb and failure occurred at just below 150,000 lb, the analytical strains at these load levels are compared to the test results. The test design value was set at $0.0065-$ in/in of strain based on the failure strains of the single-frame compression tests previously described, so no failures should be expected at strains less than this value. Principal strains from the nonlinear analysis at 90,000 lb and at $150,000 \mathrm{lb}$ are shown in Figs. 17 and 18, respectively. Maximum and minimum strain values are 0.00647 and $-0.00486 \mathrm{in} / \mathrm{in}$. at $90,000 \mathrm{lb}$ and 0.0106 and $-0.0111 \mathrm{in} / \mathrm{in}$. at $150 \mathrm{kips}$. The peak strains in both tension and compression at 90,000 $\mathrm{lb}$ are at the frame flange edges. At this loading, the panel has already buckled and bending strains are developing at the flange edges as the skin deforms. There are buckles in each the positive and negative $\mathrm{z}$ directions, so large compressive and tensile strains can develop in different bays and in the IML and OML. Other peak strains are in the web of the frame above the keyhole in compression. However the largest strains at 150,000 lb develop at the panel edges in both tension and compression. Additionally, peak strains occur at the frame flange edge in tension. The keyhole is not the location of highest strain in the 150,000 lb loading. The peak strains can only be seen easily in the refined-mesh region but appear to be occurring in the regions just above and below the refinedmesh region, where the mesh is not dense enough to pick up the very small strain concentrations.

Experimental full-field axial and shear strains on the OML for the center section of the panel (viewed by the Vic cameras) are shown at a load of 147,000 lb in Figs. 19 and 20, respectively. Peak strains occur at the edge of viewing area at the restraints along the unloaded edges. Strains at failure reach approximately -0.016 , which is significantly greater than the design strain and these locations are identified in the figure. These strain peaks occur in locations which correspond to the peak locations along the edge found in the analytical results.

Experimental strains in the loading direction in web of the frame 0.3 inches above the keyhole are shown in Fig. 21 for both frames for the center stringer. These strains remain linear to approximately $120,000 \mathrm{lb}$ when there is a jump in strain. However from this load to failure, there is no further indication of any load redistribution in the frame. These strains remain less than $0.005 \mathrm{in} / \mathrm{in}$. through the entire load range. These results indicate that the frames remain fully-capable of carrying load until panel failure and that this location may not be as critical under this loading as originally assumed.

\section{Failure}

The first sounds indicative of local failures occurred at 90,000 lbs. Also at 90,000 lb, separation could be seen between the frame flange edge and the skin in skin bays where the buckling occurred and skin deflected away from the flanges. The panel continued to carry load as separation continued at each bay. The loading increased to 147,000 lbs when the panel failed across the width as shown in Fig. 22. Failure of the panel occurred across the third bay above the center stringer, which was the last fully painted bay but does not correspond to a region of the finite element model where the mesh was refined. More detailed information of the failure locations is shown in Fig. 23 where the failure at the edge of the restraint, which continues under the restraint to the edge of the panel, occurs midbay. Failures in the frame flange-to-skin bond and at the keyhole are also evident. The failure passes through all the locations of predicted peak strains. While some damage occurred at the frame flange edge due to local buckling of the skin, this damage did not lead to global failure of the panel. Based on the strain results and photographic evidence, the failure appeared to initiate at the panel edge at the restraint and progress through the keyhole and the damaged flange region. Pictures indicate that failure initiated in the corner of the stringer and frame web intersection on the right frame when looking at the IML.

At the failure load of 147,000 lbs, the full-field test data shows the maximum out of plane deflection through the bay where the failure occurred as shown in Fig. 16. At this load, full-field test data also shows strain peak values at the edges where the restraints contact the panel as shown in Fig. 19. Shear strain results also show low strains except for peaks at the edges as shown Fig. 20. These results indicate that edge effects played a role in the failure of the panel. These edge effects influenced the failure of the two-frame panel but not the single-frame specimen described earlier, so even though both configurations have failures through the keyhole region, the initiation of failure was different. Since these edges in the two-frame panel are not completely representative of the conditions in a real aircraft structural component, a similar panel in a real aircraft may sustain higher loads prior to failure. However, since the strains at the frame flange edge and at the keyhole were also high, it is unlikely that the edge effects caused the failure to be significantly lower than if the edges had not been a problem. In any event, the test demonstrated that the PRSEUS minimum gage configuration could withstand stability loading beyond its strength capability. 


\section{Relate Back to Global Model}

The initial global analysis and sizing of the HWB aircraft indicates that the PRSEUS configuration is sufficiently light to meet the minimum weight required for the concept. The detailed panel analysis supports this theory. The panel meets the maximum anticipated span-wise compression loads from the global FEM analysis. This initial analysis supports the global optimization results that show that the PRSEUS concept is not buckling critical since it can meet the loading requirements even with the minimum gauge configuration. The test panel supported 73,000 $\mathrm{lb} /$ frame without frame buckling and, in fact, the panel failed in a strength mode rather than a stability mode. This result indicates that panels with a minimum gage skin designed by the $2 \mathrm{P}$ load condition can support at least 90 percent of the intended loading. Adjustments to frame spacing or the addition of material in the frame can raise that number to meet the design requirement.

The integrated PRSEUS concept meets the necessary requirements of the innovative structural configurations and manufacturing techniques to keep the aircraft cost-effective despite the unconventional airframe geometry and consequential loading of near-flat panels.

\section{Concluding Remarks}

Analysis and testing of a full-scale frame-stiffened panel loaded in uniaxial compression is one step along the way to validation of the Pultruded Rod Stitched Efficient Unitized Structural concept for heavily loaded aircraft components. In the current study analytical and experimental results indicate that the configuration can meet the requirements of the loading in both strength and stability in the span-wise direction of the centerbody of a hybrid wing body aircraft. Current analysis and testing of the frame element under axial compressive loading demonstrates the benefit a hybrid wing body configuration gains using a PRSEUS integral frame and stringer panel. This ability to sustain loads significantly greater than the skin buckling load is a key element in solving the structural challenges of the HWB concept with the integrated PRSEUS configuration.

\section{References}

${ }^{1}$ Liebeck, R. H., "Design Of The Blended-Wing-Body Subsonic Transport", 2002 Wright Brothers Lecture, AIAA Paper 2002-0002, August 2002.

${ }^{2}$ Velicki, A. 2009. "Damage Arresting Composites for Shaped Vehicles," NASA CR-2009-215932.

${ }^{3}$ Karal, M., "AST Composite Wing Study - Executive Summary”, NASA/CR-2001-210650, Prepared for NASA, Langley Research Center under Contract NAS1-20546, March 2001.

${ }^{4}$ NASA TCAT Phase I Study (Novel Blended Wing Body Structural Concepts), Velicki, A., Contract NNL04AA36C CLIN 0001, July 2004.

${ }^{5}$ Air Vehicle Technology Integration Program (AVTIP), Delivery Order 0059: Multi-role Bomber Structural Analysis, AFRL-VA-WP-TR-2006-3067, Krishna Hoffman, MAY 2006, Final Report for 14 December 2004 - 08 May 2006, AFRL-VAWP-TR-2006-3067.

${ }^{6}$ Velicki, A. and Thrash, P.J., "Advanced Structural Concept Development Using Stitched Composites", 49th AIAA/ASME/ASCE/SHS/ASC Structures, Structural Dynamics, and Materials Conference, 7-10 April 2008, Schaumburg, IL, AIAA Paper 2008-2329.

${ }^{7}$ Jegley, D., 2010 “Influence of Impact Damage on Carbon-Epoxy Stiffener Crippling,” American Society for Composites meeting, Sept 2010, Dayton OH.

${ }^{8}$ Yovanof, N.P., "Advanced Structural Stability of a Non-Circular BWB-Shaped Vehicle", 50th AIAA Structures Dynamics and Materials Conference, May 4-7 2009, Palm Springs, CA.

${ }^{9}$ Velicki, A., Jegley, D.C., and Thrash P.J., "Airframe Development for the Hybrid Wing Body Aircraft", 47th AIAA Sciences Meeting, AIAA-2009-932, Jan 5-8 2009, Orlando, FL.

${ }^{10}$ Velicki, A., and Thrash P.J., "Blended Wing Body Structural Concept Development", Aircraft Structural Design Conference, Oct 14-16 2008, Liverpool, UK.

${ }^{11} \mathrm{Li}$, V., and Velicki, A., "Advanced PRSEUS Structural Concept Design and Optimization", 12th AIAA/ISSMO Multidisciplinary Analysis and Optimization Conference, AIAA-2008-5840, Sept. 10-12 2008, Victoria, British Columbia, Canada.

${ }^{12}$ Jegley, D.C., Velicki, A., Hansen, D., "Structural Efficiency Of Stitched Rod-stiffened Composite Panels With Stiffener Crippling", 49th AIAA/ASME/ASCE/SHS/ASC Structures, Structural Dynamics, and Materials Conference, 7-10 April 2008, Schaumburg, IL.

${ }^{13}$ Velicki, A., Yovanof, N., Baraja, J., Linton, K., Li, V., Hawley, A., Thrash, P., DeCoux, S., and Pickell, R., "Damage Arresting Composites for Shaped Vehicles phase II Final Report," Prepared for NASA, Langley Research Center under Contract NNL07AA48C, Oct. 2010.

${ }^{14}$ MSC. NASTRAN MSC.NASTRAN, Version 2005r3, MSC Software Corporation, 2 MacArthur Place, Santa Ana, CA 92707. 


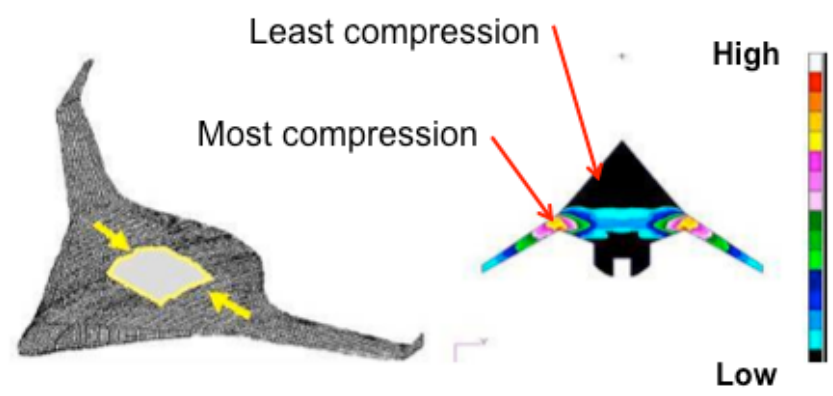

Figure 1. Span-wise loading during 2.5-g maneuver. Running loads are shown in lb/in.

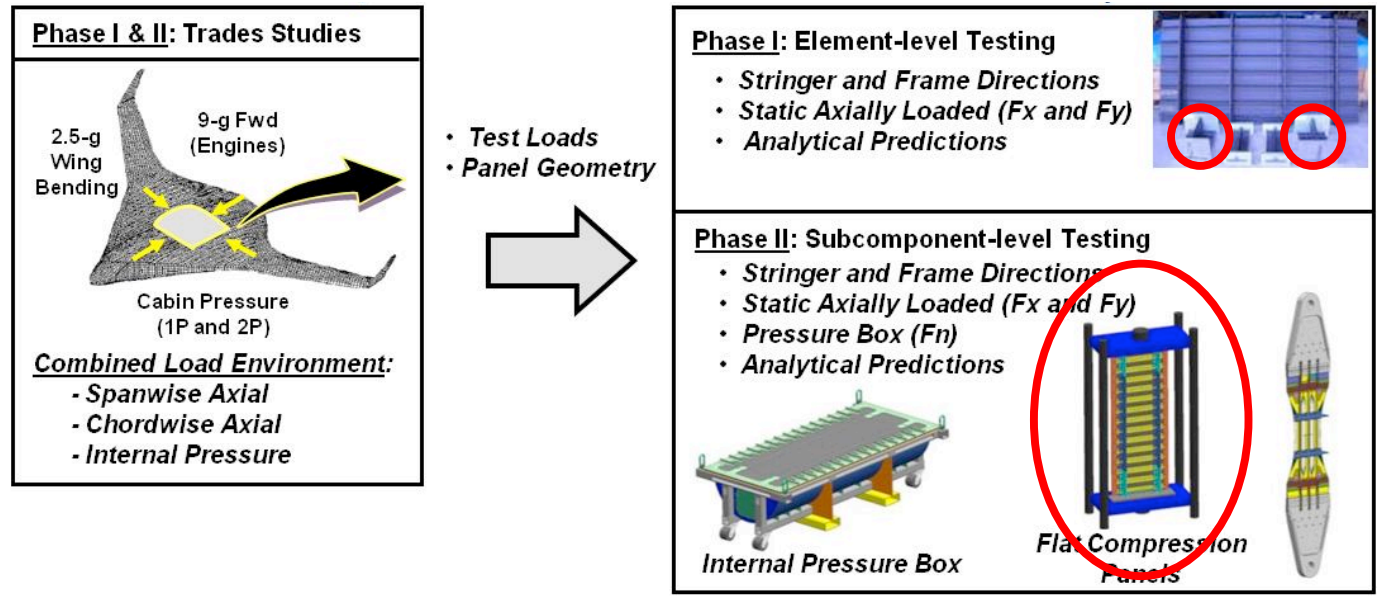

Figure 2. Structural development building block approach.

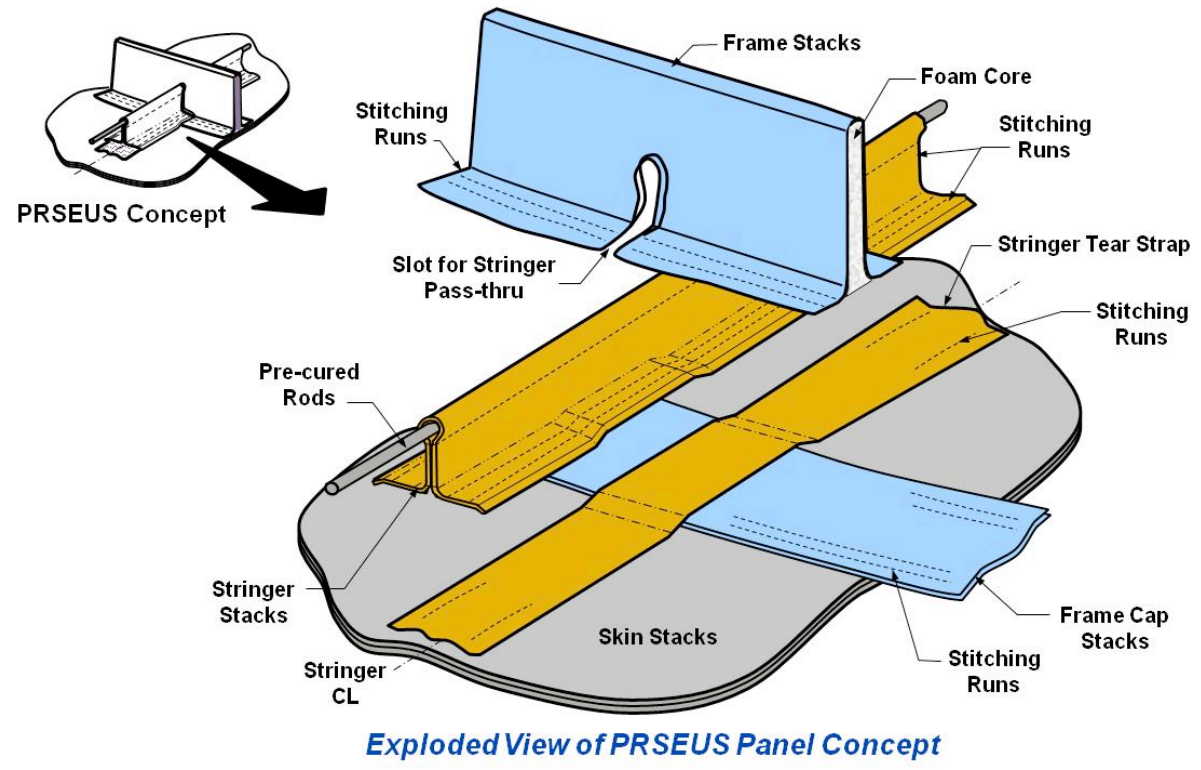

Figure 3. PRSEUS stiffener intersection. 


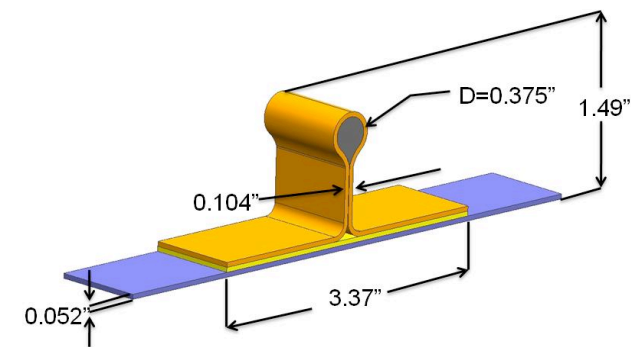

Figure 4. Rod-stiffener geometry.

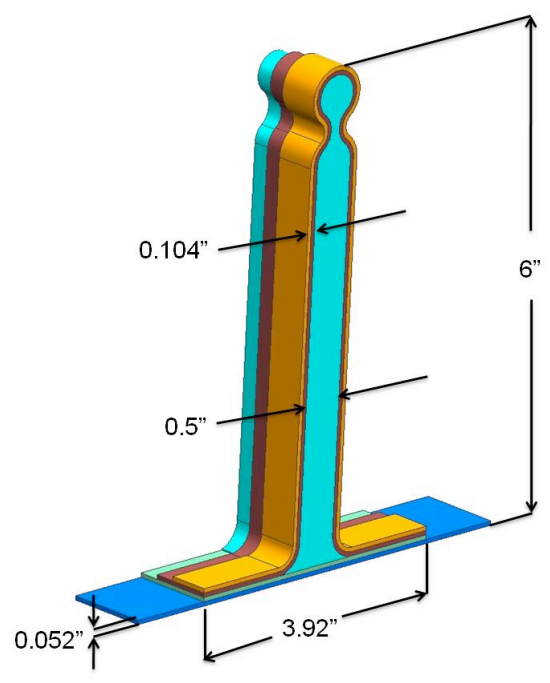

Figure 5. Frame geometry.

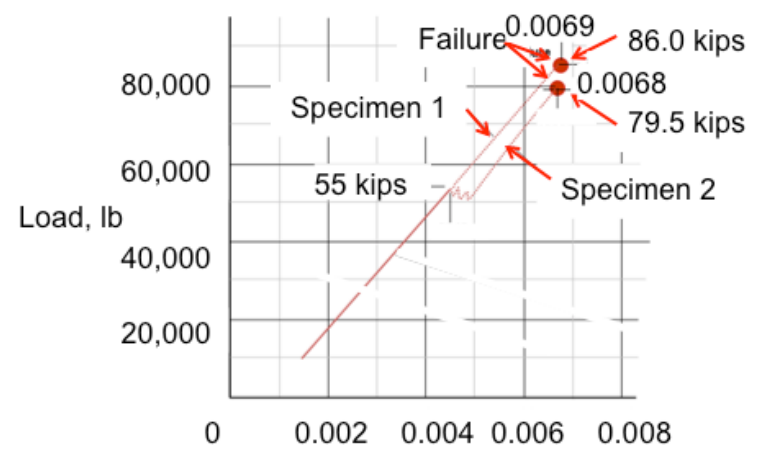

Nominal compressive strain, in/in.

Figure 6. Single-frame compression specimen results.

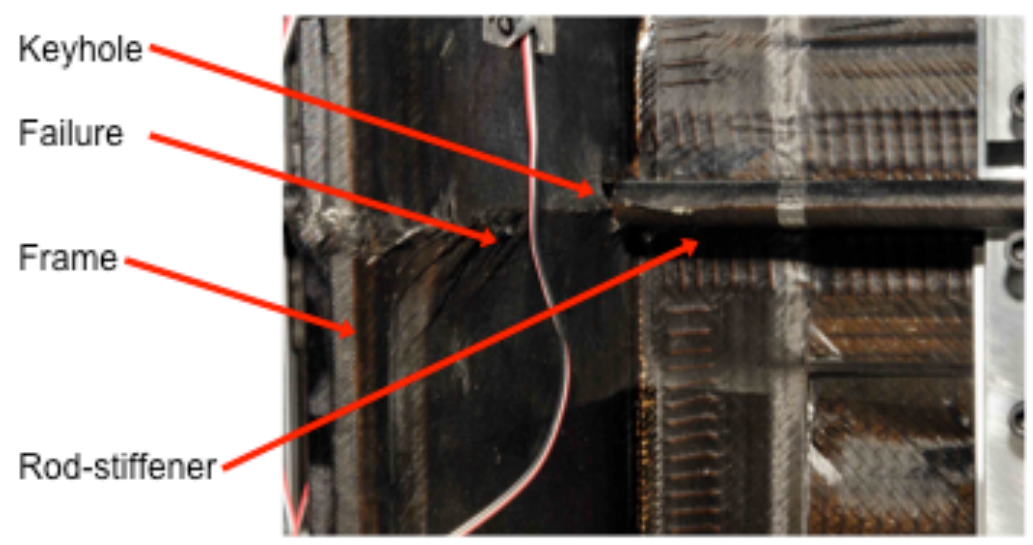

Figure 7. Single-frame compression specimen failure. 


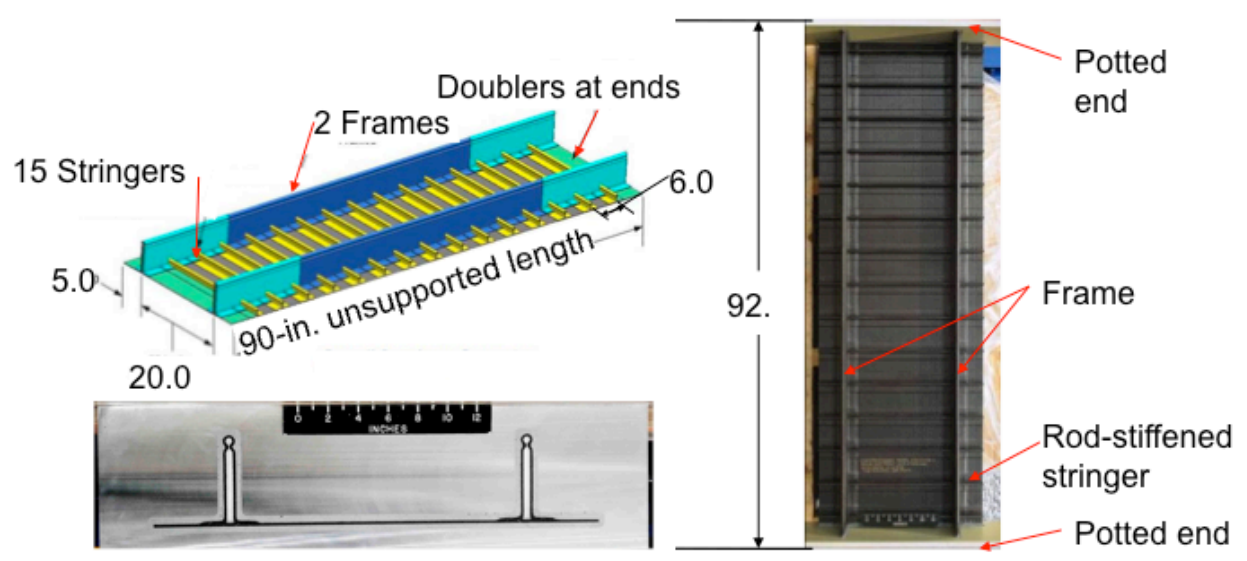

Figure 8. Subcomponent panel. Dimensions are in inches.

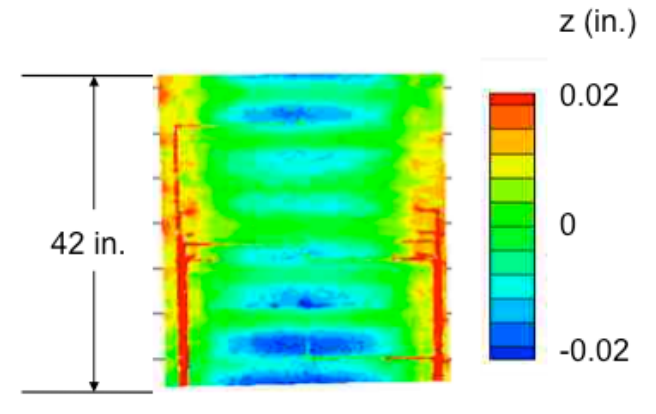

Figure 9. Initial imperfection in center region of OML (red lines along edges represent strain gages and wires, not the panel surface).

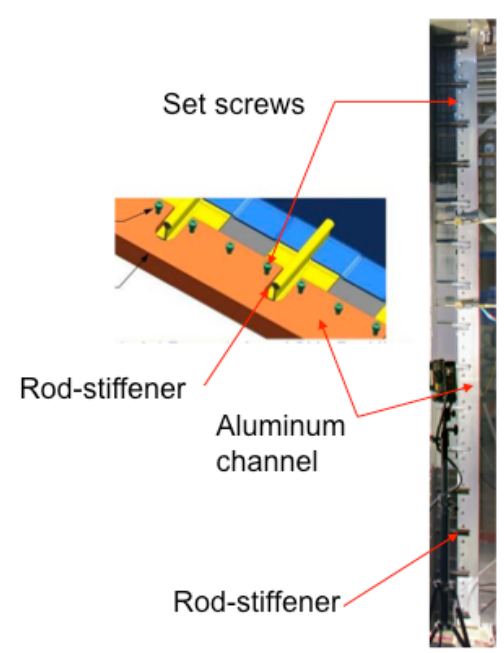

Figure 10. Edge restraints. 


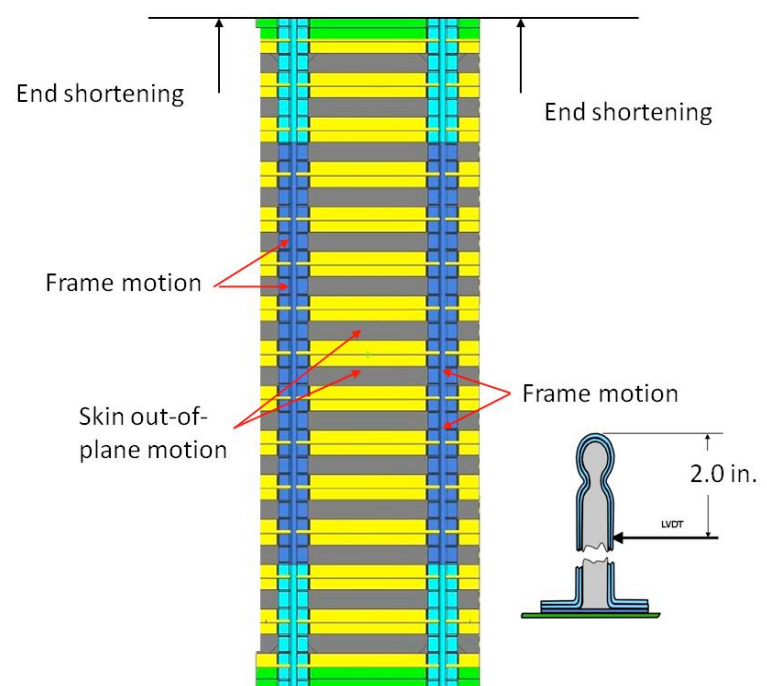

a) Displacement measurement locations.
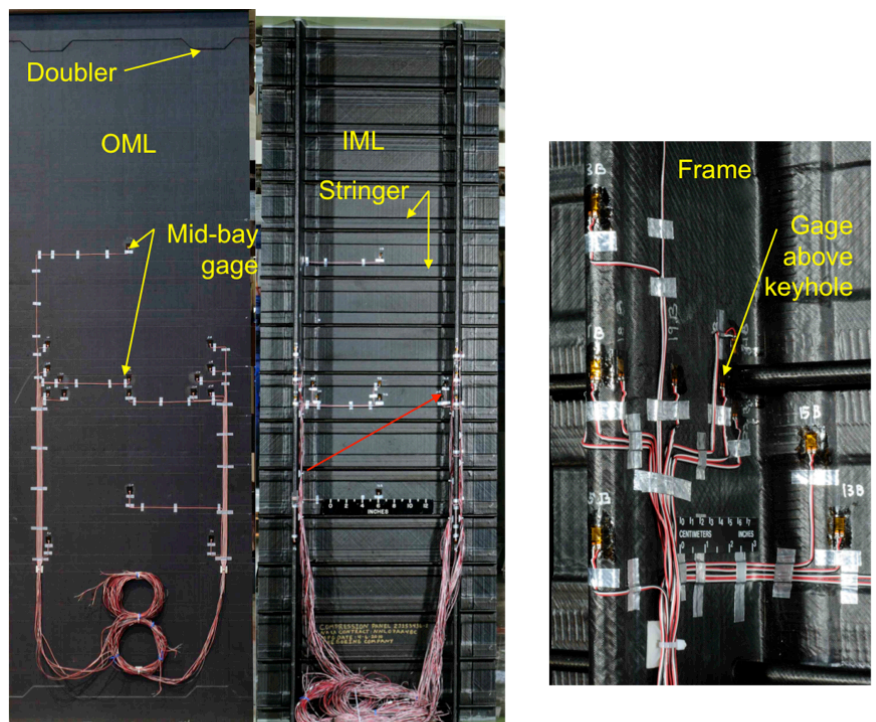

b) Strain gage locations.

Figure 11. Instrumentation.

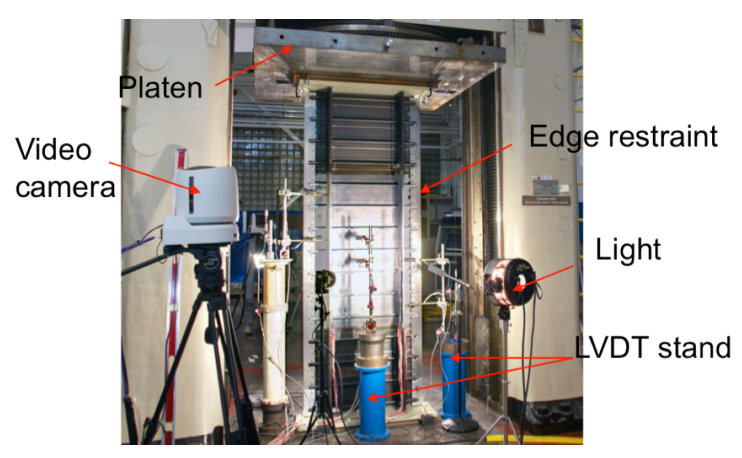

Figure 12. Subcomponent panel in test machine.

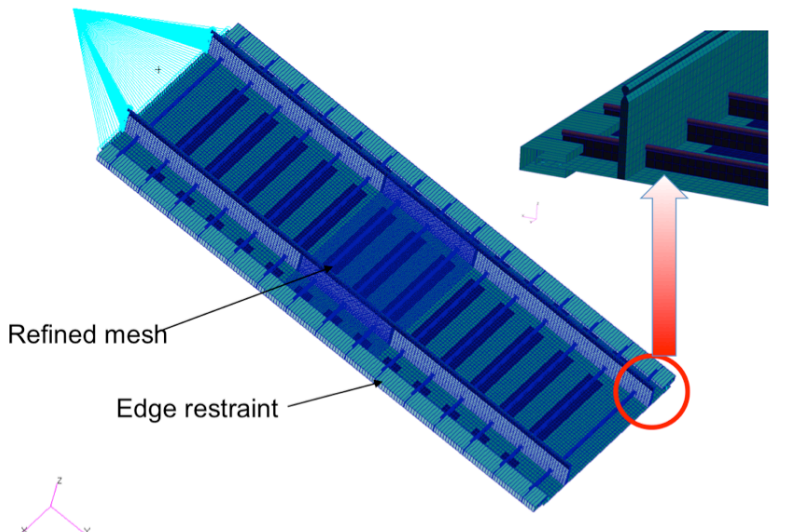

Figure 13. Finite element model.

American Institute of Aeronautics and Astronautics 


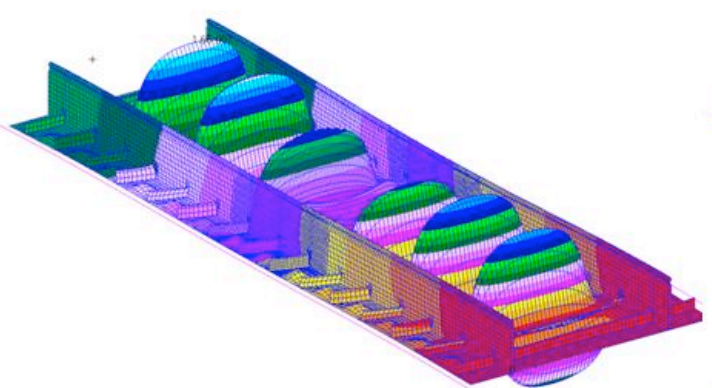

Skin buckling at 59,000 $\mathrm{lb}$

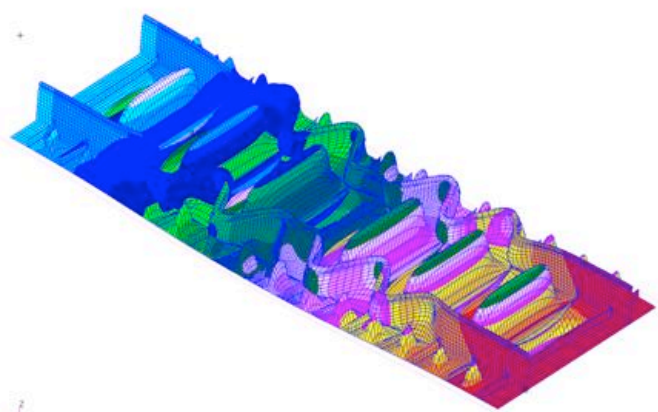

Global buckling at 207,000 lb

Figure 14. Predicted buckling mode shapes.

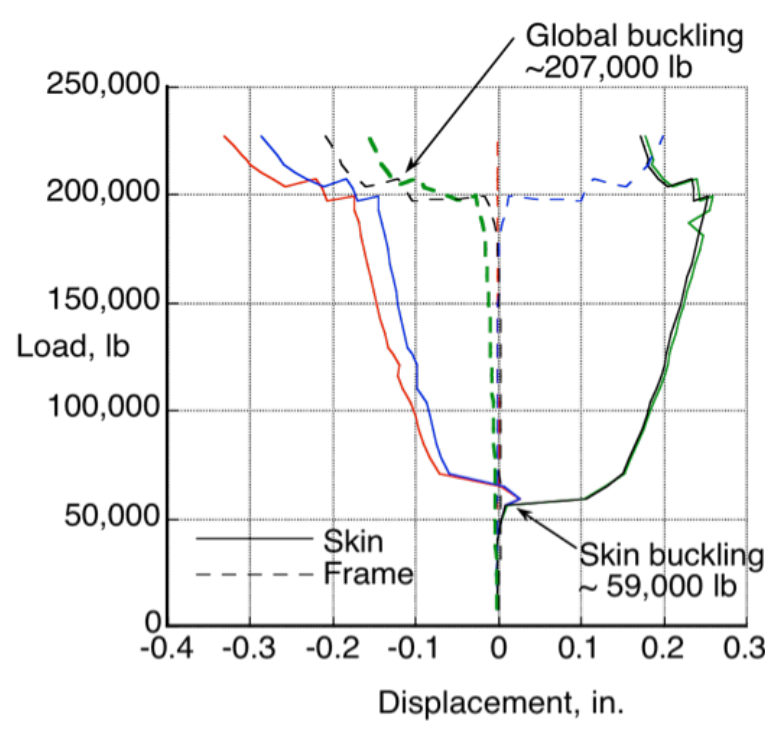

Figure 15. Predicted displacements.

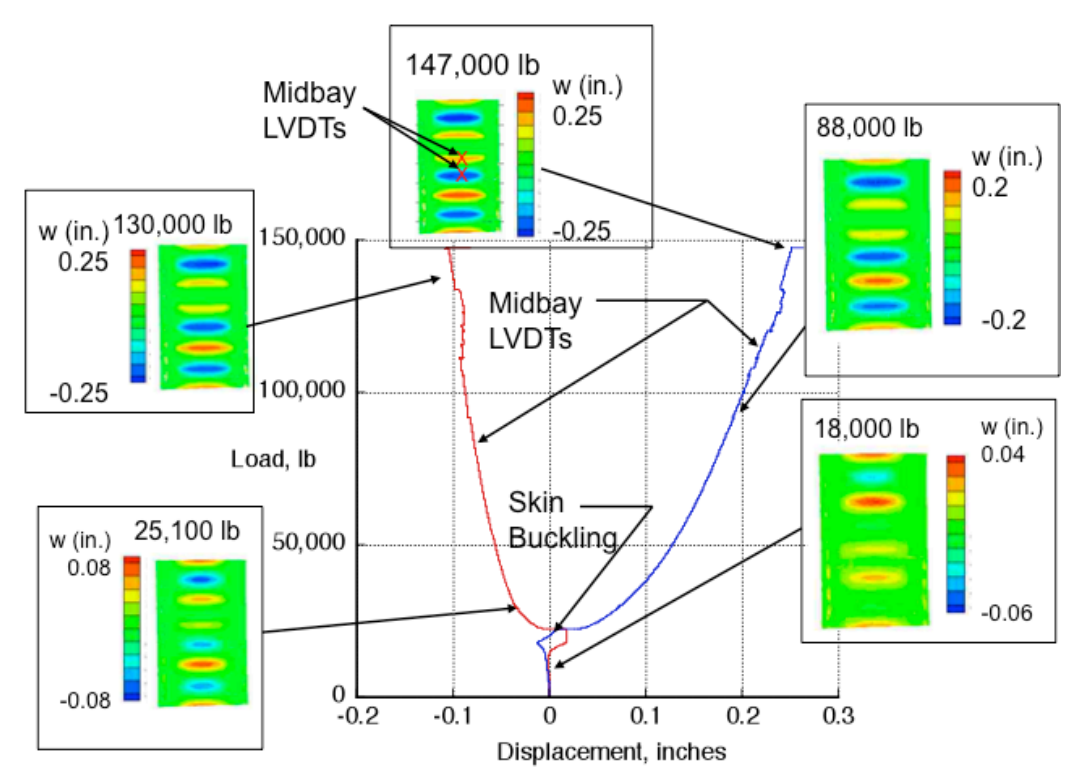

Figure 16. Experimental displacements.
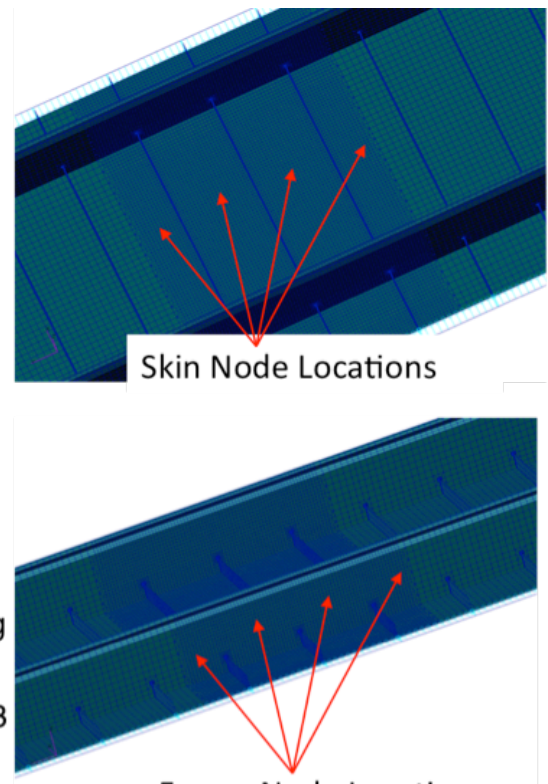

Frame Node Locations

American Institute of Aeronautics and Astronautics 


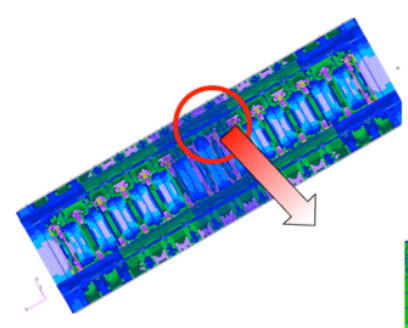

Peak strains at flange edges

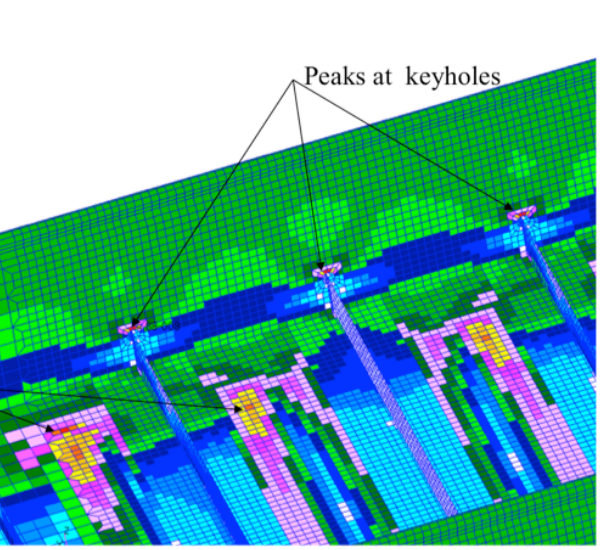

$-0.00486$

a) Minimum principal keyhole strains.

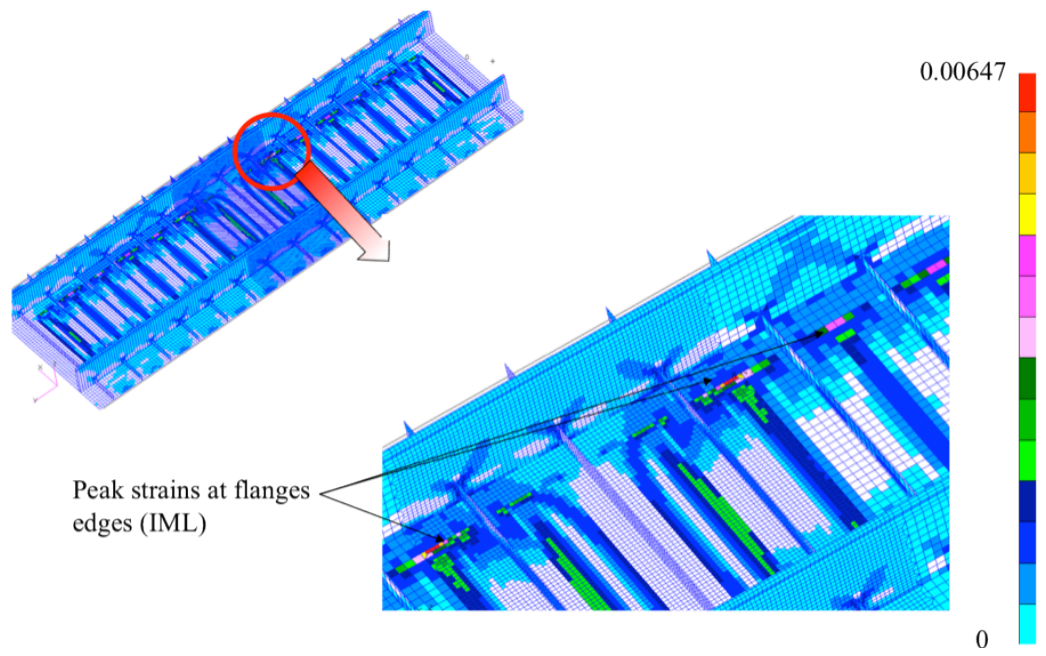

b) Maximum principal flange edge strains on IML.

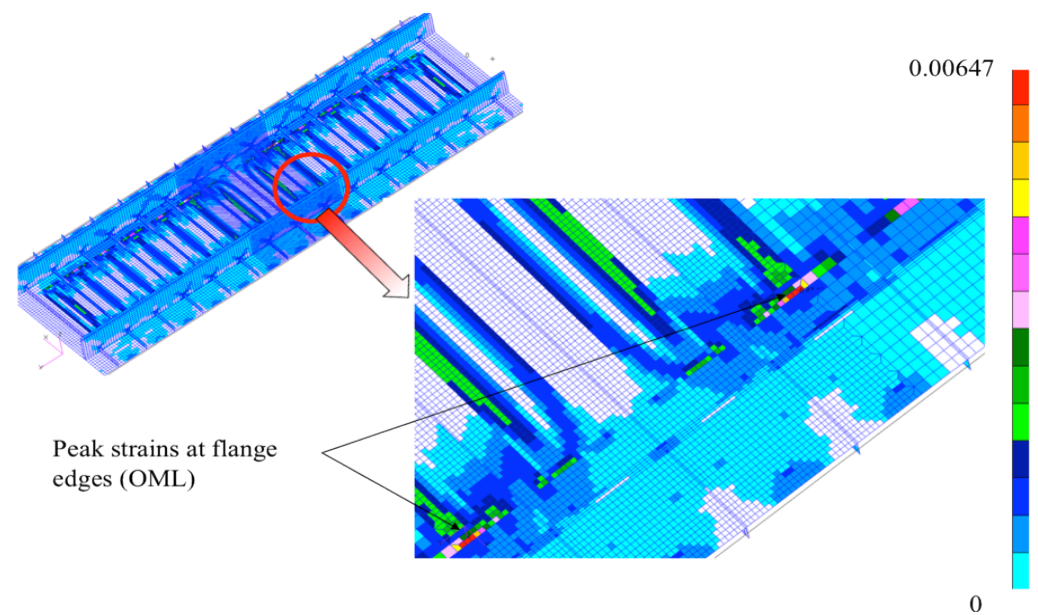

c) Maximum principal flange edge strains on OML.

Figure 17. Predicted strains at $90,000 \mathrm{lb}$. 


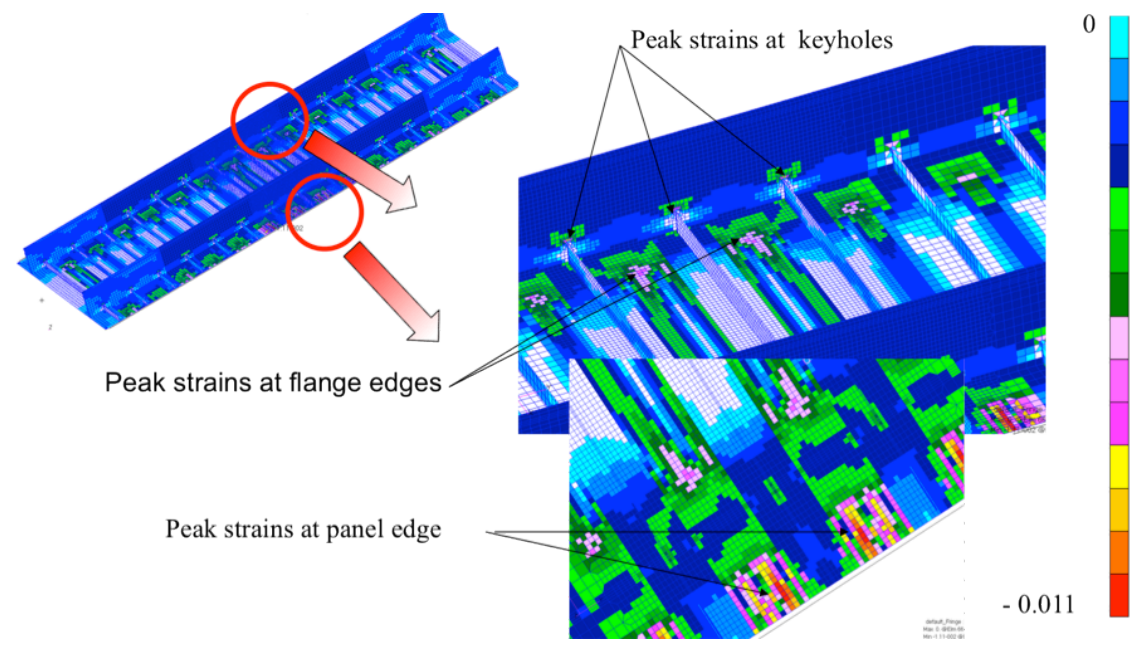

a) Minimum principal strains.

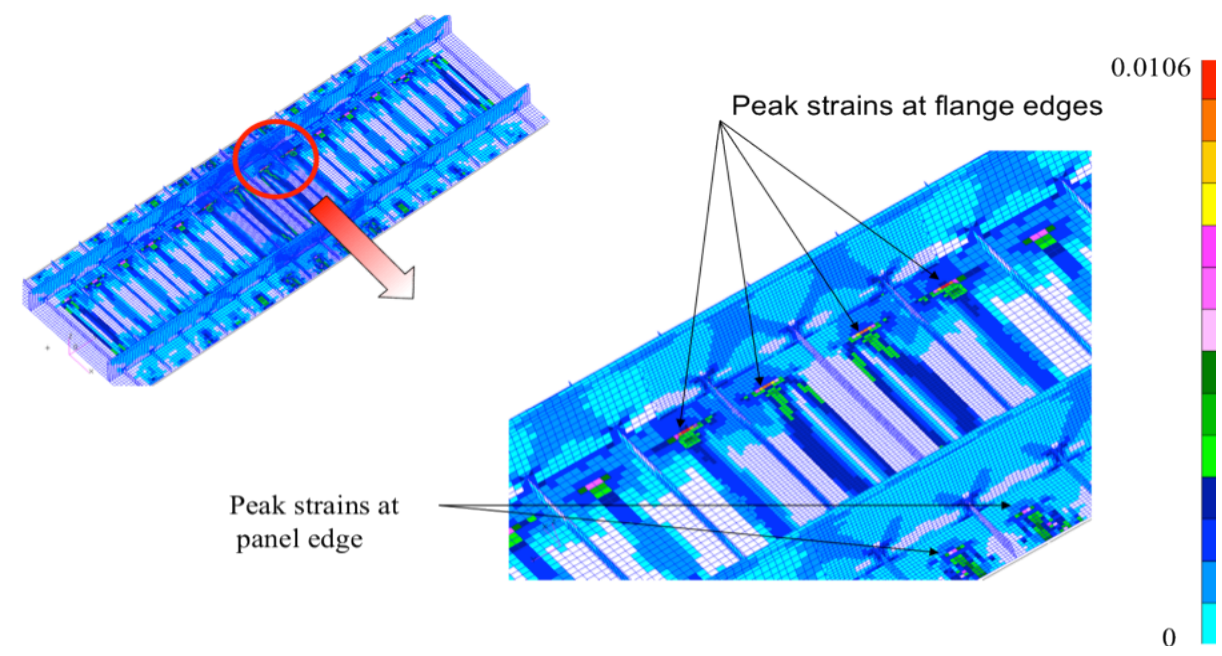

b) Maximum principal strains.

Figure 18. Predicted strains at $150,000 \mathrm{lb}$.

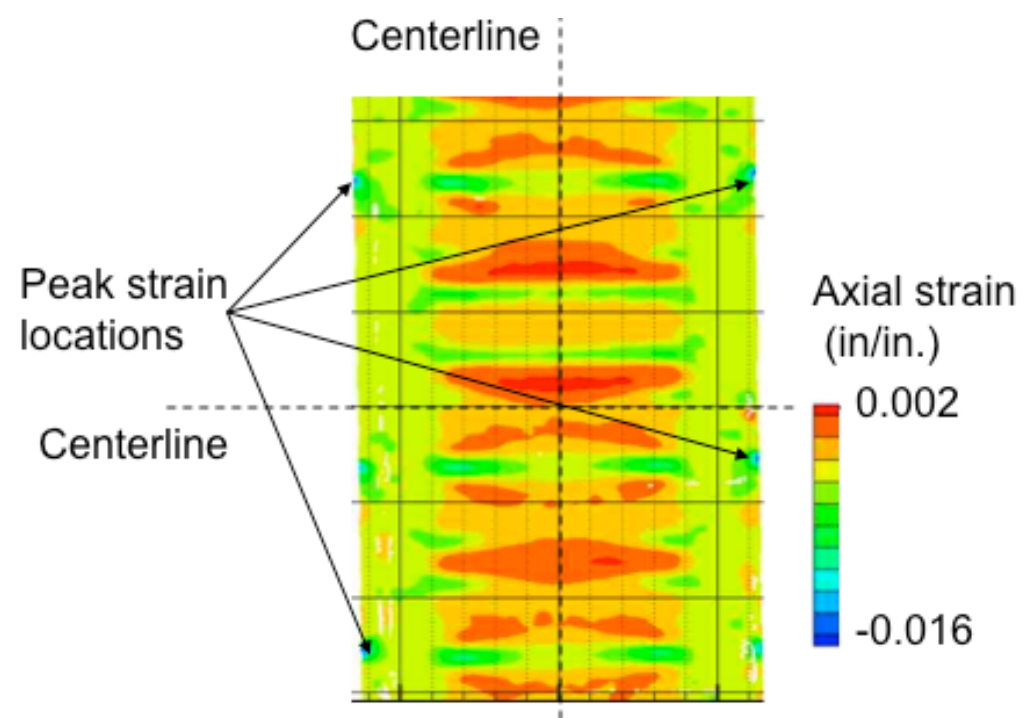

Figure 19. Full-field axial strains at $147,000 \mathrm{lb}$ load.

American Institute of Aeronautics and Astronautics 


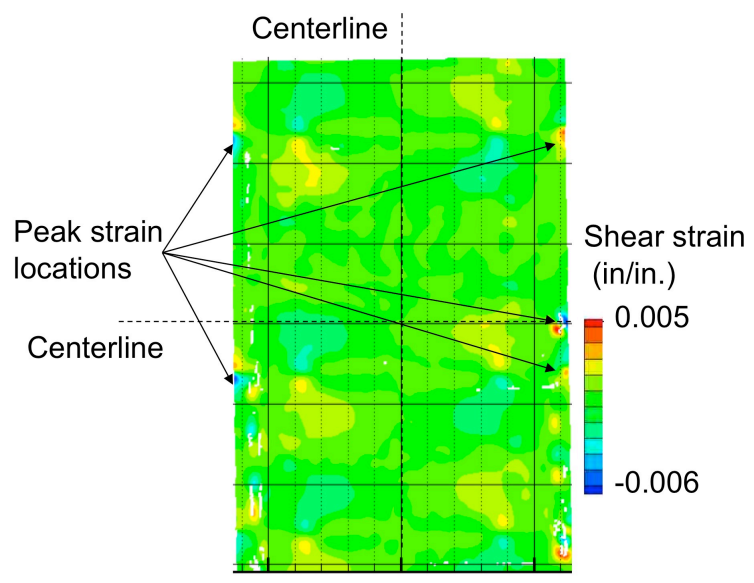

Figure 20. Full-field shear strains at $147,000 \mathrm{lb}$ load.

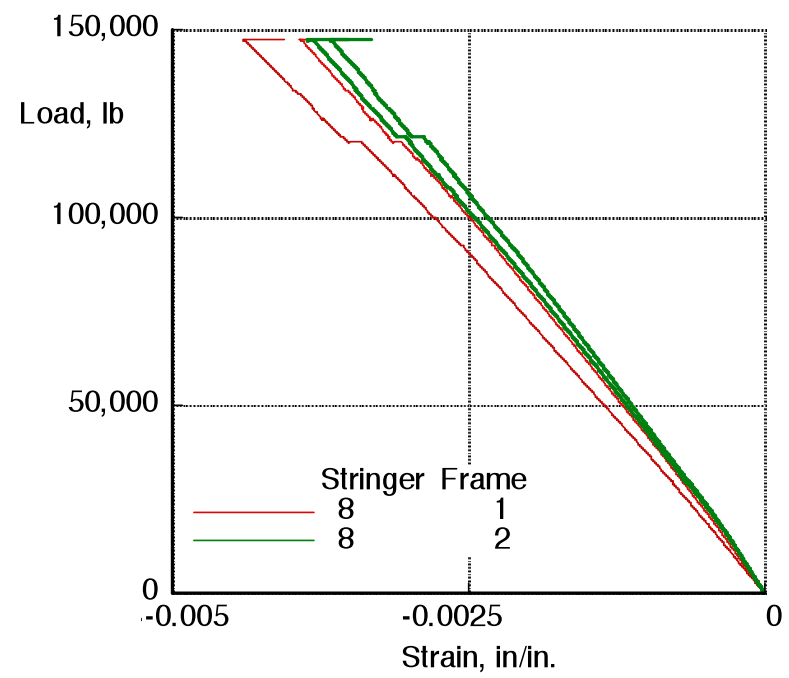

Figure 21. Measured strains in frame web immediately above keyhole.

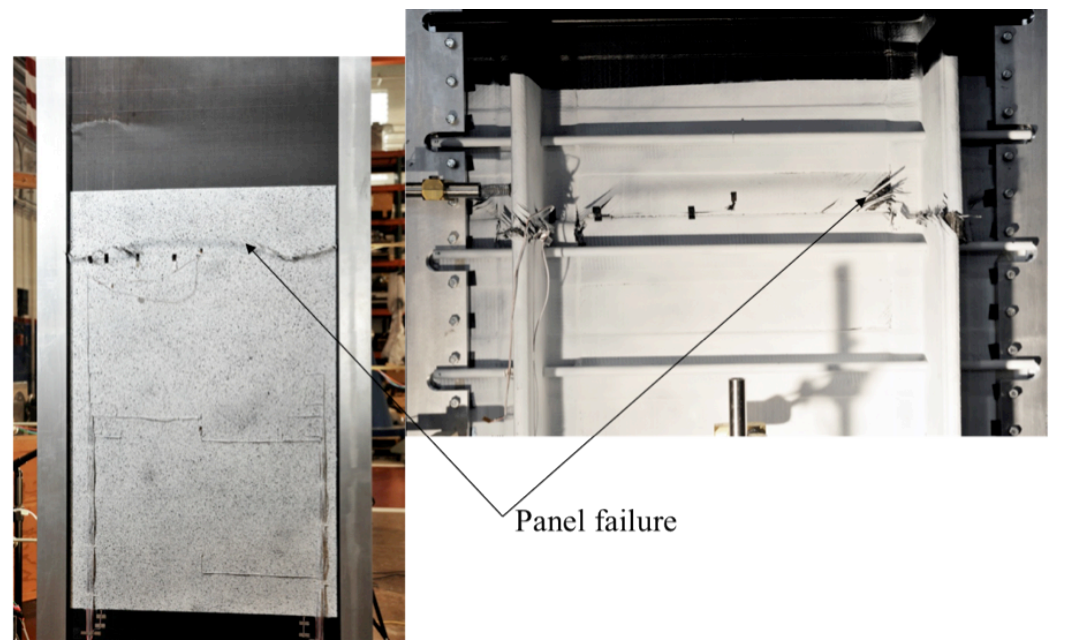

Figure 22. Panel failure across width of panel. 


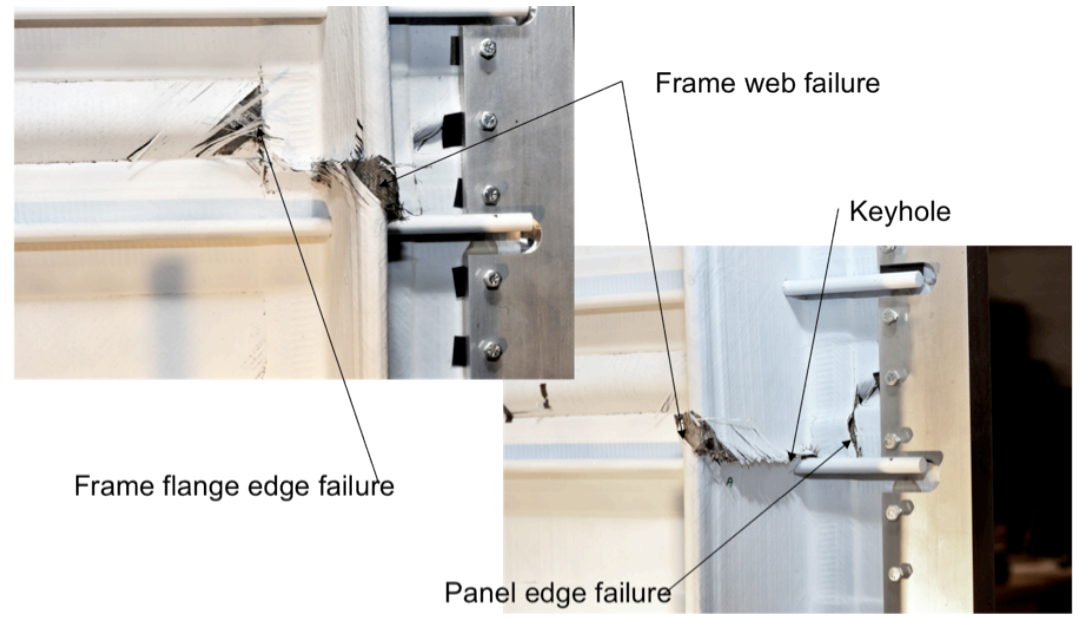

Figure 23. Failure of frame flange edge, keyhole and edge region. 